\title{
Innovation Strategy Research of Shaanxi People's Livelihood
}

\author{
Yanxue Wang \\ Xi'an Peihua University, Xi'an Shaanxi, 710077, China
}

Keywords: People's livelihood technology, Agricultural science and technology, Challenges, The guiding ideology, Strategic goals, Innovation

\begin{abstract}
Along with the information age of the Internet with the reform and opening up successively, and the development of science and technology of the people's livelihood in our country are like a duck to water, great changes have taken place, especially in modern science and technology as the forerunner of agriculture science and technology of the people's livelihood has become the only way for modern rural agricultural reform. This paper discusses the Shaanxi challenges faced in the process of development of agricultural science and technology, and puts forward the future agricultural development strategy of the overall framework and innovation strategy.
\end{abstract}

\section{Introduction}

After 2010, Shaanxi entered a new stage of agricultural science and technology for development, but also faced with the optimization of industrial structure adjustment of tasks at the same time, this is related to the improvement of agricultural comprehensive production capacity in the province and the growth of farmers' income. More importantly, Shaanxi agricultural science and technology development also shoulder the historical task of building a well-off society in an all-round way. From short-term analysis, agricultural development of Shaanxi agricultural science and technology faces many challenges, such as food safety in the production of pressure increasing, highlights, agricultural commodities competitiveness of agricultural products quality problems and issues of the farmers' income growth. So from the point of the long-term development of agriculture in the province, the new phase of the Shaanxi province agricultural science and technology must be under huge pressure at the same time actively seeking technology innovation and promoting strategies to meet the demand of the future agricultural development in the province.

\section{The development challenges Shaanxi agricultural structure development of agricultural science and technology}

\section{Agricultural structure adjustment to the challenges of agricultural science and technology development in Shaanxi province.}

First of all, the agricultural structure adjustment makes the agricultural products and its processed products gradually realized the standardization, efficiency, and the varieties, this also need to face to the Shaanxi agricultural science and technology for the future development of long-term research subject. Especially in an international market, the need from fruits and vegetables, animal husbandry and special advantage such as agriculture, concentrated power of science and technology are in conformity with international standards of deep research and development, to create a characteristic brand of agricultural products, and to establish a stable and reliable technical support system. So in the future, Shaanxi agricultural science and technology development and to form their own technical service system, take the market as the guide, in order to benefit as the goal, with an emphasis on safety, high quality and high efficiency, learning the foreign advanced experiences as will, makes every effort to diversify, scientific advantages of agricultural products in the province of production, processing, storage, packaging, transportation and trade links, do it step by step to agricultural science and technology research projects.

On the other hand, the future of agriculture of Shaanxi is faced with agricultural production advantages to the central region to gather the trend of development. Due to the enormous enrichment of agricultural science and technology, it must also be breakthrough technology innovation system, in 
order to support the small peasant economy as the leading factor in the traditional model of seeking new strategic positioning and the superiority of science and technology field, the corresponding strategic adjustment in agricultural technology and resource integration.

Increasing farmers' income for the challenges of agricultural science and technology development in Shaanxi province.

To realize agricultural income is Shaanxi new stage of agricultural science and technology and the central task of economic development. In Shaanxi province of Shaanxi, and in southern Shaanxi Guan-zhong, agricultural economic region there are challenges of increasing farmers' income as the agricultural science and technology development, such as the need to optimize the agricultural structure, the promotion of scarce resource alternative agricultural technology to promote the increase of agricultural products, but also improve pesticide industrial inputs such as element to the efficiency of agricultural production. So, Shaanxi enormous challenges brought by the farmers' income is the need to through more novel way of intensive agriculture technology to realize the agricultural products of high yield per unit area, and reduce the production cost of agricultural products.

\section{Protect food for the challenges of agricultural science and technology development in Shaanxi province.}

Shaanxi new stage of agricultural food security not only to meet the demand of the nation's basic level, more important is to meet the demand of Shaanxi province, the development to coordinate the relationship between the agricultural science and technology and food safety. Shaanxi province agricultural science and technology, therefore, at present the main challenges to ensure food security degree of four aspects.

First, agricultural science and technology to make full use of and integrating the method of natural science and the theory of management science, by building an early warning system for agricultural products market in the province and inputs regulatory system to planning technology of agricultural market information and product information. Also want to establish a sensitive agricultural monitoring system to do the provincial food safety warning zone, to ensure the absolute safety of food.

Second, the need to further promote deepening traditional plant breeding techniques and molecular biology technology, and vigorously develop between them and the genetic engineering technology in combination with each other. The current Shaanxi province agricultural science and technology is to focus on biotechnology, mining using crop genetic resources. So in the future, how to reasonably develop new, high quality art crop varieties, cultivation techniques, how to promote modern farming will be Shaanxi agricultural science and technology in food demand side faces significant challenges.

Third, in Shanxi province agricultural science and technology are not only at the technical level to do innovation, but also to do innovation in the development of food resources. It is mainly to improve the structure of food as the guide to ensure that the food supply of safe and effective. For Shanxi agriculture at present, the breakthrough tradition food crops as raw materials for the primary problem is the top priority, only so Shaanxi is also in the more established based on the new use, new features and new development pattern of food deep processing factory, hope to promote Shanxi agricultural crops throughout the overall competitiveness of the domestic market.

Fourth, in order to realize the agricultural production increment, but also by developing a large number of biological technology to replace the traditional pesticide, and the development of non-toxic pollution-free low new pesticides residues, gradually replace the heavy use of chemical fertilizer in Shanxi agriculture. In Shanxi agriculture disease suppression, should stick to control the agriculture veterinary medicine from its source and the principle of chemical fertilizer, and the agricultural products processing, transportation and other links insist to use new technology and new materials, build the best safety evaluation technology system for food safety. Finally, through biotechnology innovation to effective control of deep processing of possible harmful substances in food, and thus improve the food's nutrition value and quality, and improve the safety of genetically modified food. To sum up, Shanxi agricultural development should follow is given priority to with agriculture science and technology development, sustainable development as the important guiding ideology, to optimize the food safety standards for the mechanism of agricultural science and 
technology production system, strengthen the agricultural science and technology of agriculture in the province of Shanxi technical manipulation of the force ${ }^{[1]}$.

\section{Shanxi agricultural development of science and technology innovation strategy framework design in the future}

The strategic principle of agricultural science and technology in province.

Conventional technology and the fusion of new and high technology

First condition to improve technical level of agricultural production is agricultural technology routine solid, again on this foundation development based on the conventional technology concept derived out by high and new technology, it is the first principle of development of Shanxi future agricultural science and technology. With the help of powerful agricultural production range of conventional technology adaptability not only can increase the high and new technology research and application of practicality and possibility, also can build the new standard for traditional agricultural technology reform, promote the rapid effective fusion of high and new technology with conventional technology.

Conventional fusion of technology and innovation technology

Shanxi last in province belongs to our country's economy, so it is necessary to follow the national agriculture science and technology development strategy of the principle of market economy and the international common practice, through bold innovation of science and technology in agricultural high-tech industries demonstration zone to drive the agricultural advantage projects, and at the same time attaches great importance to the support for the agricultural research institutions. In addition to the existing horticulture, animal husbandry and agricultural product processing industry and other special advantage agricultural projects, should also be emphasized based on the agricultural development of independent innovation, organization in the province of agriculture science and technology, public relations, the formation of a number of with independent intellectual property rights of original agricultural science and technology achievements. Given the current resources are increasingly scarce in the province and the increasing deterioration of the ecological environment, with the help of traditional agricultural technology to promote independent innovation of agricultural productivity and the related technology and project is necessary.

Results the effective transformation of agricultural scientific and technological innovation and technology

In economically developed countries, agricultural scientific and technological progress brought about by the contribution rate of agricultural production will be higher than $80 \%$, but our country is only $45 \%$, in Shanxi, the figure is $33 \%$, this shows that Shaanxi province agricultural science and technology and great rise in space, so the Shanxi agriculture must adhere to the principle of science and technology development, led, and successful transformation of agricultural scientific and technological achievements, the academic value. Also attaches great importance to the application of science and technology, to develop the technology innovation and promotion of closely with each other, based on the Shanxi effectively solve the "issues of agriculture, farmer and rural area", this also is helpful for further industrialization of agricultural high-tech achievements.

Alternative technology and labor intensive technology resources integration

Shanxi agricultural development strategic goal is the same with the state, it is to build a harmonious society as the foundation to give full play to the application of labor resources in the province, to do the abundance of agricultural economic and agriculture science and technology in province. So in Shanxi in the new stage of agricultural development should be to adhere to the principle of priority of employment as the main, and to develop labor-intensive technology support, let the labor-intensive industries in the province and rural employment problem. In the new stage, Shanxi agriculture must also be combined with land and water resources in the province instead of new technologies, construction of high labor intensity and industry returns qi agricultural science and technology system, make the resource alternative technology and labor-intensive technology fast, can improve the efficiency of agricultural production in the province in the short term. 


\section{The strategic task of agricultural science and technology in province.}

Strengthening the management of agricultural science and technology system reform

As described in Shanxi province of the main challenges faced by agriculture also pointed out that while Shanxi agricultural science and technology has developed to a certain height, but science and technology management system still needs further reform. System of the agricultural industry, led by science and technology management system, not only conducive to agricultural science and technology innovation, also can promote the development of agricultural economy in the province efficiency, and openness, such as trans-regional agricultural planting and trade cooperation, and even the international trade of agriculture. Therefore should be held in every year in the province of Shanxi province agriculture expo to promote the industry at home and abroad to communicate with each other in agricultural science and technology development experience, but also bring in the province of large-scale project investment.

Expand agricultural science and technology

Shanxi province should be the principle, key technology on agricultural science and technology innovation of agricultural science and technology of various expansion strategy, such as molecular biology, the agricultural ecology in arid areas such as solid theory, genetics, material engineering, create more practice opportunities, to seek technological breakthroughs. In northern Shanxi, the course, the three main areas to develop organic agriculture in Guanzhong plain, green ecological agriculture and water-saving agriculture, will be the long-term productivity and comprehensive production capacity of agriculture as a key development target, meet the new phase of the broad masses of urban and rural residents in Shanxi agriculture agricultural products dietary structure to improve, and then improve the nutritional quality of agricultural products.

The development of information network agriculture strategy

The 21st century is the age of the Internet information, so the Shanxi agriculture should also keep pace with The Times, vigorously develop information network technology, engineering materials technology and standardized technology, the advanced technology into the order of agricultural science and technology, forming the core content of Shanxi agriculture as a whole system, make the equipment level of Shanxi agriculture and agricultural production efficiency in stable state for a long time.

The popularization of agricultural science and technology education

Shanxi is agricultural education, agricultural science and technology development in Shanxi province in the future strategy of agricultural science and technology strategy is also should be to the agricultural vocational education and the popularity of farmers technology skills and practice training, this is keep in Shanxi agriculture the basis of long-term sustainable development. Currently in Shanxi province of the rural population has exceeded 20 million, accounts for more than $60 \%$ of the population in Shanxi, which means developing the rural human resources, implement strategy of agricultural science and technology education in Shanxi province the importance of agriculture in the future. It is a huge and long-term project, but also the future development in Shanxi province agriculture, necessary to enhance the level of science and technology to do ${ }^{[2]}$.

\section{Shanxi agricultural science and technology innovation strategy of the development of the future}

Based on the Shanxi agricultural science and technology, the future of agricultural development in the province must be based on agricultural science and technology management system and innovation mechanism of the two big aspects, on the basis of efforts to stabilize agricultural science and technology innovation framework into each field of agricultural science and technology, achieve agricultural science and technology innovation of careful.

\section{Protect the natural resources.}

The life for agricultural development of Shanxi in addition to the agricultural science and technology is the natural ecological environment and resources available, on soil, air, vegetation and water protection, Shanxi agriculture is the future. So in the province should be from the level of environmental protection, the research on how to improve agricultural production system, protection 
of vegetation, the quality of ground water and soil and water conservation of advanced agricultural technology.

\section{Strengthen the agricultural products processing and transport of goods.}

Agricultural products processing and transportation level also determines the advancement of agricultural science and technology, so in Shanxi province should pay more attention to this on the one hand, the innovation of the reform, such as establishing can detect and eliminate animals and feed products contaminated with integrated test antivirus system, and establish based on rapid determination and analysis of characteristics of agricultural products quality evaluation system. Also note that it is best to agricultural products as raw materials to replace agricultural production materials, ensure the development of agricultural science and technology environmental protection and energy saving.

\section{Mechanization of agriculture science and technology equipment and innovation.}

The realization of the agricultural science and technology is to use and agricultural science and technology and equipment. In Shanxi province has been gradually realized the development and innovation of agricultural mechanization, gradually realize the principle of mechanical and electrical integration, there are defects, but the overall mechanization innovation such as for forestry, feed, vendor operations, hydraulic, electrical and other machinery and equipment and the technique of agricultural science and technology is incomplete, and promotion propaganda also enough, haven't been able to achieve full area in the province's agricultural machinery management and application of global change science and technology, so it is also an important task for the future development of Shanxi agriculture ${ }^{[3]}$.

\section{Summary}

This article from the development challenges, strategic design, and innovation strategy, and other aspects discusses the future development prospect of Shanxi province agricultural science and technology, is to prove productive forces of science and technology for the importance of agricultural development in the region. As an important link of science and technology of the people's livelihood, can only continue to bring benefits to the people, the development innovation brings its own development in the future the possibility of more. Shanxi province in the development of agricultural science and technology innovation strategy is also suitable for other regions, as long as appropriate to the thinking of innovation according to its own local characteristics, can drive the area economic development, it will make people a better life.

\section{Acknowledgments}

This article is Xi 'An PeiHua college in 2015 field project, the project name is Under the perspective of new silk road economic belt Shaanxi people's livelihood development of science and technology innovation research, project number: PHKT20150709.

\section{References}

[1] Ning Miao, Zhou Xiuping. Under the perspective of sustainable development, China's agricultural science and technology development strategy. Journal of scientific research management,2009,30(6):156-162.

[2] Wang Yanxue. The path research of Shanxi science and technology development of the people's livelihood. Journal of cooperation in economy and technology ,2015,(7):37-38.

[3] Bai Xusheng. Shaanxi province agricultural science and technology development strategy research. Northwest agriculture and Forestry University of science and technology,2013,11-26. 